\title{
Alcohol use in the military: associations with health and wellbeing
}

\author{
Michael Waller ${ }^{1,2^{*}}$, Annabel C. L. McGuire ${ }^{1}$ and Annette J. Dobson ${ }^{2}$
}

\begin{abstract}
Background: This study assessed the extent to which alcohol consumption in a military group differed from the general population, and how alcohol affected the military group's health and social functioning.

Methods: A cross sectional survey of military personnel $(n=5311)$ collected self-reported data on alcohol use (AUDIT scale) and general health, role limitations because of physical health problems (role physical), and social functioning scores (SF36 subscales). Logistic regression was used to compare drinking behaviours between the military sample and a general population sample, using the categories risky drinkers ( $>2$ units per day), low risk drinkers ( $\leq 2$ standard drinks per day) and abstainers. Groups in the military sample with the highest levels of alcohol misuse (harmful drinking AUDIT $\geq 16$, alcohol dependence AUDIT $\geq 20$, and binge drinking) were also identified. Linear regression models were then used to assess the association between alcohol misuse and SF36 scores.
\end{abstract}

Results: There were fewer risky drinkers in the military sample than in the general population sample. There were also fewer abstainers, but more people who drank at a lower risk level ( $\leq 2$ standard drinks per day), than in a sample of the general population. Harmful drinking and alcohol dependence were most commonly observed in men, younger age groups, non-commissioned officers and lower ranks as well as reserve and ex-serving groups. Alcohol misuse was clearly associated with poorer general health scores, more role limitations because of physical health problems, and lower social functioning.

Conclusions: Although risky drinking was lower in the military group than in the general population, drinking was associated with poorer health, more limitations because of physical health problems, and poorer social functioning in Defence members. These results highlight the potential benefits for Defence forces in reducing alcohol use among members, in both those groups identified at highest risk, and across the military workforce as a whole.

Keywords: Alcohol, Military, Health, Drinking, General population

\section{Introduction}

Historically there has been a strong tradition of alcohol consumption in military populations [1] and moderate consumption is still considered to be an important catalyst for bonding and cohesion in the military [2]. However, there are a number of negative effects of heavy alcohol use. It has been linked to physical conditions, including liver damage, cancers, cardiovascular disease, and injuries [3], and has been shown to be associated with both major depression [4] and increased symptoms

\footnotetext{
* Correspondence: m.waller@uq.edu.au
${ }^{1}$ The University of Queensland, Centre for Australian Military and Veterans

* Correspondence: m.waller@uq.edu.au
${ }^{1}$ The University of Queensland, Centre for Australian Military and Veterans Health, School of Public Health, Herston Road, Herston 4006, Australia ${ }^{2}$ The University of Queensland, School of Public Health, Herston Road, Herston 4006, Australia
}

of Post-Traumatic Stress Disorder [5]. This study reports measures of alcohol consumption, identifies high risk groups, and examines the association between drinking and general health, limitations because of physical health problems, and social functioning in Australian military personnel.

As well as impacting on health, heavy alcohol use in military settings has been shown to be associated with a number of behavioral and performance issues, such as 'being passed over for promotion', arrests for 'drink driving' [6] and 'violence on homecoming' [7]. Workplace outcomes such as lateness, leaving early, low performance, and injuries are also more common among heavy drinkers in the United States (US) Defense force [8]. 
The evidence for performance impairment from the effects of a 'hangover' in military groups is inconclusive [9]. Nevertheless, some studies have shown that alcohol use disorders are associated with poorer functioning [10-13]. In a number of these studies the poorer functioning was observed in harmful and dependent drinkers, but not in those who drank at lower levels, or in weekly binge drinkers $[11,10]$. Therefore, heavy alcohol use, in particular, may have major effects on the health of a Defence force member and their ability to deploy.

Within a military, certain occupational groups or exposures may be associated with alcohol misuse. Higher levels of drinking have been identified among single and younger personnel $[1,11]$. Similarly, having problems at home around the time of deployment, and poor unit leadership have been reported as predictors of higher drinking levels [2]. Deploying with one's parent unit and a high level of camaraderie in the unit have also been associated with higher drinking [2].

Consistent with a perceived culture of drinking in military personnel, studies from the United Kingdom (UK) and the US have shown higher alcohol consumption in the military generally [14], and among Naval personnel $[15,16]$ compared to civilians. However, results from US studies in a similar period were inconsistent. For example, Polich showed that rates of alcohol abuse were similar between military and civilian groups, once demographic differences had been accounted for [17]. Ballweg reported that while non-drinking was higher in civilians, a higher proportion of military personnel were likely to drink at low risk levels (1-2 standard drinks a day) compared with their civilian counterparts [18].

The first aim of this study was to compare the prevalence of drinking in currently serving and former members of the Australian Defence Force (ADF) with a nationally representative sample of civilians. A 2010 study, limited to currently serving personnel, showed that alcohol use disorders were significantly lower in Australian military personnel compared to the Australian community [19]. To gain a more comprehensive picture the present study also included both current and ex-serving personnel and compared the proportions of abstainers and low risk drinkers in these groups.

The second aim of the study was to identify which groups among current and former ADF personnel were most likely to report harmful drinking and binge drinking. While certain characteristics (such as being young and single), have been previously reported as risk factors of these behaviors $[1,11]$, the aim was to identify whether other characteristics such as service, rank and employment status (e.g. current or ex-serving) were also risk factors for drinking to a harmful level or binge drinking. The identification of such groups can inform policies to reduce harmful drinking in the ADF.

The final aim was to examine the association between drinking and general health and the ability to function normally. While other studies have shown that those with alcohol dependence have poorer health and work outcomes $[11,13,12]$, the present study was able to observe whether those who drink at lower levels also had poorer outcomes.

\section{Methods}

\section{Study groups}

The Bougainville Deployment Health Study and the East Timor Deployment Health Study were cross-sectional surveys, undertaken in 2008 [20, 21], to assess the health and experiences of the current and former ADF members deployed to these countries between 1997 and 2005. All 4,775 veterans known to have deployed to Bougainville were invited to participate. The East Timor study invited a representative sample of 3,999 veterans from a deployment of 19,705. Each study also included comparison groups of personnel in the ADF at the same time but who were not deployed to the country studied ( $n=2,363$ and $n=2,501$ respectively). For this paper the data from the deployed and comparison groups of these two studies were combined to provide a cohort of serving and former ADF personnel who served in the period from 1997 to 2005, and completed a study survey in 2008. The combined sample invited to take part in the survey was 12,829 (as 809 were in both the Bougainville and East Timor studies).

\section{Recruitment}

An invitation was sent to the 12,829 individuals to complete a survey on paper or online. Reminder cards/ emails were sent within one month and follow-up phone calls were then made to non-responders. The period of recruitment for the study was from November 2007 to January 2009. Informed consent for participation in the study was obtained from each participant. Demographic characteristics were available for the full list of people invited to the study from the ADF personnel database (PMKeyS). The overall survey response rates for people who provided complete data on the AUDIT scale for the Bougainville and East Timor studies were $43 \%$ and $41 \%$ respectively (overall $41 \%, N=5311$ ). Most people completed the survey online $(87 \%)$. The response rates were higher among women, older age groups, Air Force personnel (compared to Navy and Army personnel), officers (compared to lower ranks) and currently serving ADF members (compared to former members, Table 1). In the dataset used for analysis, the proportion of women was $12.9 \%$. 
Table 1 Australian Defence Force sample survey response rates by demographic characteristics (numbers and row percentages)

\begin{tabular}{|c|c|c|c|}
\hline & $\begin{array}{l}\text { Responder to } \\
\text { AUDIT scale }\end{array}$ & $\begin{array}{l}\text { Non-responder to } \\
\text { AUDIT scale/survey }\end{array}$ & $\begin{array}{l}\text { Chi-squared test } \\
\text { p-value }\end{array}$ \\
\hline \multicolumn{4}{|l|}{ Gender } \\
\hline Male & $4628(41.0)$ & $6671(59.0)$ & \\
\hline Female & $683(44.6)$ & $847(55.4)$ & 0.0061 \\
\hline \multicolumn{4}{|l|}{ Age } \\
\hline $20-29$ & $659(28.0)$ & $1696(72.0)$ & \\
\hline 30-39 & $2382(39.8)$ & $3603(60.2)$ & \\
\hline $40-49$ & $1629(48.4)$ & 2024 (51.6) & \\
\hline $50-59$ & $559(57.3)$ & $417(42.7)$ & \\
\hline $60+$ & $81(56.6)$ & $62(43.4)$ & $<0.0001$ \\
\hline \multicolumn{4}{|l|}{ Service } \\
\hline Navy & $1076(39.1)$ & $1674(60.9)$ & \\
\hline Army & $3831(41.7)$ & $5366(58.3)$ & \\
\hline Air Force & $404(45.8)$ & $478(54.2)$ & 0.0014 \\
\hline \multicolumn{4}{|l|}{ Rank } \\
\hline Officer & $1602(51.4)$ & $1512(48.6)$ & \\
\hline Non-commissioned Officer & $3056(44.1)$ & 3879 (55.9) & \\
\hline Other ranks & $641(23.3)$ & $2108(76.7)$ & $<0.0001$ \\
\hline \multicolumn{4}{|l|}{ Employment status } \\
\hline Full time & $2883(50.2)$ & 2864 (49.8) & \\
\hline Reserve & $1723(45.5)$ & $2062(54.5)$ & \\
\hline Ex-serving & 705 (21.4) & 2589 (78.6) & $<0.0001$ \\
\hline
\end{tabular}

These studies were approved by the Australian Defence Human Research Ethics Committee, the Department of Veterans' Affairs Human Research Ethics Committee, and the University of Queensland Behavioural \& Social Sciences Ethical Review Committee.

\section{National Drug Strategy Household Survey (NDSHS)}

Results published from the 2010 National Drug Strategy Household Survey (NDSHS) were used to compare levels of drinking between Australian military personnel and the general population [22]. The NDSHS sample included 26648 people over the age of 12 (94\% over the age of 18). The alcohol consumption patterns compared between the ADF and NDSHS were: abstainers, low risk drinkers (no more than two standard drinks per day), and high risk drinkers (more than two standard drinks per day). In this manuscript we refer to drinking more than two standard drinks per day as 'risky drinking'.

\section{Measurements}

Alcohol use was compared between the following subgroups of the ADF: age (20-29, 30-39, 40-49 and 50+), gender, service (Navy, Army and Air Force), rank (officer, non-commissioned officer and other ranks), ADF employment status (full-time, reserve or ex-serving) and marital status (single/other, living with partner, married and divorced/separated).

The Alcohol Use Disorders Identification Test (AUDIT) is a 10 item scale which can be used to identify hazardous and harmful patterns of alcohol consumption [23]. The scale focuses on current drinking behaviours and experiences with alcohol in the previous 12 months. The first eight items have five response options that are scored from 0 to 4 and the last two items have three response options scored 0, 2 or 4. The responses are summed to give a score from 0 to 40 . People who score 0 are abstainers, while those who score 1-7 are considered low risk drinkers. Scores between 8 and 15 represent people who drink in excess of guidelines for low risk consumption (hazardous drinking; more than 10 grams of alcohol a day) [24]. In the analyses, a score of $\geq 16$ on the AUDIT scale was classified as drinking at a harmful level and a score $\geq 20$ was defined as probable alcohol dependence. Previous studies using the AUDIT scale have reported Cronbach's alpha reliability coefficients ranging between 0.69 and 0.74 , and estimates of the test-retest reliability between 0.81 and 0.98 [25].

The NDSHS report did not include results from the AUDIT scale. However, the first two questions of the AUDIT scale ask about the frequency of drinking and 
the quantity of alcohol consumed on a typical drinking day. Responses to these questions were used to estimate the number of drinks consumed in a week for each ADF study participant (see Additional file 1: Figure S1). These estimates were compared to data on the level of drinking observed in the general Australian population obtained from the 2010 NDSHS [22].

The third question in the AUDIT scale asks how frequently a respondent has had six or more drinks on one occasion. Responses to this question were used to estimate the prevalence of binge drinking. 'Binge drinking weekly or more' and 'binge drinking monthly or more' were used as separate binary outcomes in logistic regression models.

Three subscales of the Short Form (36) Health Survey (SF-36) were used to calculate the general health, role physical and social functioning scores of participants. The general health scale has five questions. The role physical scale has four questions about role limitations because of physical health problems. The social functioning scale has two questions about the impact of physical health and emotional problems on normal social activities. Each of these subscales was scored between 0 and 100, with higher scores indicating better health [26]. The SF-36 questions used generally asked about the responders' experiences in the previous 4 weeks.

\section{Statistical analysis}

The demographic characteristics of responders and nonresponders (obtained from the ADF personnel database) were compared using chi-squared tests. The proportions of people drinking at the 'risky' and 'low risk' levels and the proportions of abstainers were compared between the ADF and NDSHS samples using logistic regression. These comparisons were adjusted for age (10 year groups) and gender to account for the different demographic characteristics of the samples. For the comparisons with NDSHS data, the ADF survey results were not weighted for non-response. However, a sensitivity analysis was also undertaken which weighted the ADF survey data for non-response by service, rank and employment status.

Logistic regression models were used to compare patterns of harmful drinking (AUDIT $\geq 16$ ), alcohol dependence (AUDIT $\geq 20$ ) and binge drinking between subgroups of the ADF sample. Multiple regression models were used to compare general health, role physical and social functioning scores between people in each alcohol consumption category. These comparisons were adjusted for demographic characteristics and smoking status (current smoker, ex-smoker or never smoker), as smoking was hypothesised to be a possible confounding variable [27].
Unless specified otherwise, analyses were weighted for non-response to ensure that results were representative of the Australian Military sample invited to participate. Weights were calculated for strata defined by gender, rank, service and employment status. Statistical analyses were performed using SAS version 9.3 [28] and STATA version 10.1 [29].

\section{Results}

There were clear and consistent associations between high scores on the AUDIT scale and poorer health outcomes. Mean scores for the general health, role physical (role limitations because of physical health problems) and social functioning scales all decreased with increased AUDIT scores (Fig. 1 and Additional file 2: Table S1). Clear and statistically significant differences were observed for those who drink at a harmful level (AUDIT 16-19) and those who were alcohol dependent (AUDIT $\geq 20$ ), compared to low risk drinkers (AUDIT 1-7). Those with an AUDIT score of 8-15 also had poorer health scores compared to the low risk drinkers ( $p$-values $<0.0001)$. The health outcomes for low risk drinkers (AUDIT 1-7) were slightly better than for the abstainers $($ AUDIT $=0)$, however, these differences were not statistically significant for the general health and social functioning scales. Among those who drank at a low risk level ( $\leq 2$ drinks a day), $27 \%$ reported 'binge drinking' at least monthly. However, these 'binge drinkers' did not have significantly poorer scores on the general health and role physical and social functioning subscales compared to low risk drinkers who did not report 'binge drinking' (Additional file 3: Table S2).

Compared to the NDSHS sample, the current and former ADF members were less likely to be abstainers (OR $0.2895 \%$ CI $(0.24,0.33)$ ), and less likely to drink at a risky level (on average, more than 2 drinks a day) (OR 0.59 (95\% CI $(0.54,0.64)$ ), but more likely to drink at a low risk level (OR $2.3095 \%$ CI $(2.12,2.47)$ ) (Table 2). These patterns were observed in both men and women. The results changed only marginally when the ADF data were weighted for non-response (Additional file 4: Table S3).

The median AUDIT score in the ADF sample was 5.0 (interquartile range 3-9) and the mean was 6.9 (standard deviation 5.3). Overall $4 \%$ of participants were abstainers and $60 \%$ were low risk drinkers. Hazardous drinking (AUDIT $\geq 8$ ) was reported by $36 \%$ of responders, whereas the percentages of those drinking at a harmful level (AUDIT $\geq 16$ ) and those with probable alcohol dependence (AUDIT $\geq 20$ ) were $9 \%$ and $4 \%$ respectively.

Men were more likely than women to drink at a harmful level (AUDIT $\geq 16$ ), as were those aged 20-29 compared to older age groups (Table 3 ). The proportion of 

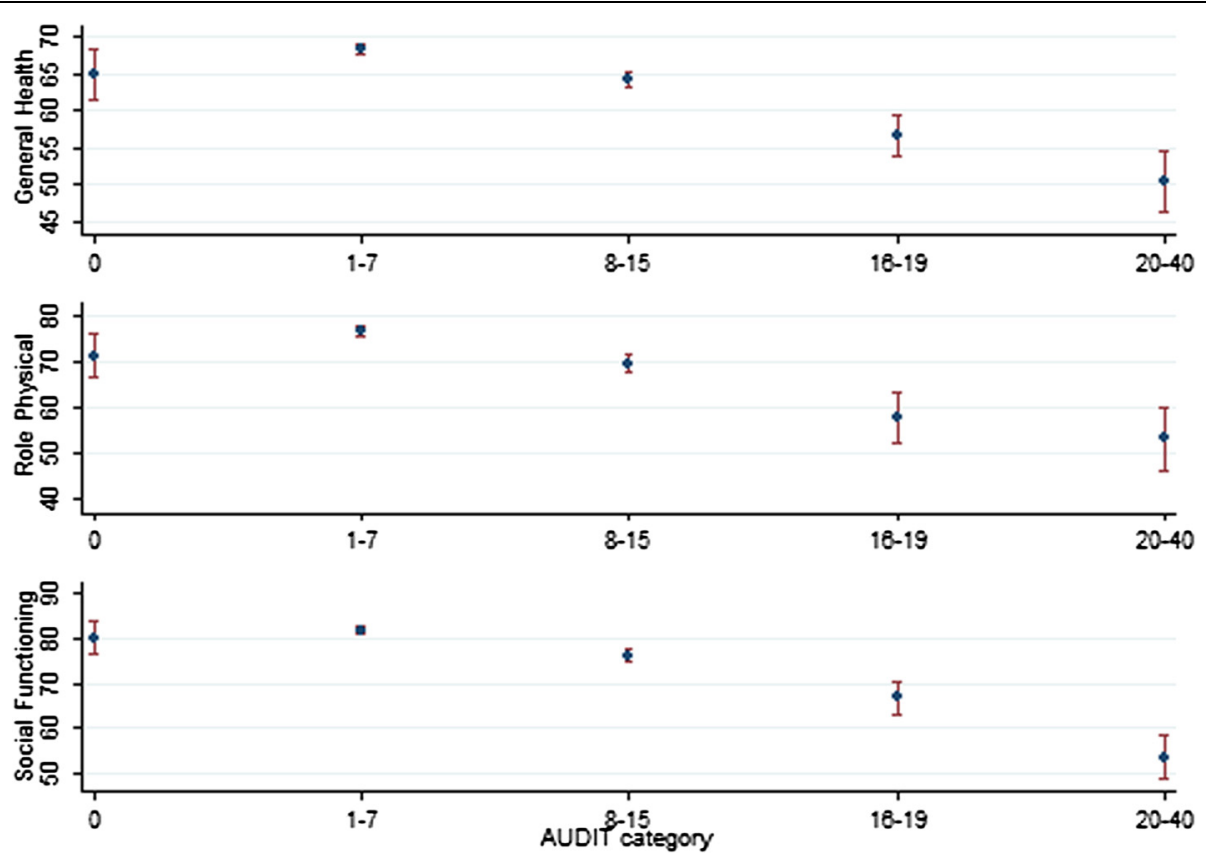

Fig 1 General health, role physical and social functioning, by alcohol use category (AUDIT scale) in the Australian Defence Force sample. Footnote: AUDIT scores 0 = Abstainers, 1-7 = low risk drinkers, 8-15 = hazardous drinking, 16-19= harmful drink, $\geq 20$ probable alcohol dependence

Table 2 Drinking behaviours in Australian Defence Force (ADF) sample compared to the general population sample (NDSHS)

\begin{tabular}{|c|c|c|c|c|c|c|}
\hline & $\begin{array}{l}\text { Percentage of risky } \\
\text { drinkers in ADF } \\
\text { sample }(\%)^{\mathrm{a}}\end{array}$ & $\begin{array}{l}\text { Percentage of risky } \\
\text { drinkers in civilian } \\
\text { sample (\%) }\end{array}$ & $\begin{array}{l}\text { Percentage of } \\
\text { abstainers in ADF } \\
\text { sample (\%) }\end{array}$ & $\begin{array}{l}\text { Percentage of } \\
\text { abstainers in civilian } \\
\text { sample (\%) }\end{array}$ & $\begin{array}{l}\text { Percentage of low risk } \\
\text { drinkers in ADF } \\
\text { sample }(\%)^{\mathrm{b}}\end{array}$ & $\begin{array}{l}\text { Percentage of low risk } \\
\text { drinkers in civilian } \\
\text { sample (\%) }\end{array}$ \\
\hline \multicolumn{7}{|l|}{ Males } \\
\hline $20-29$ & 109/551 (19.8 \%) & $36.1 \%$ & 20/551 (3.6 \%) & $13.9 \%$ & 422/551 (76.6 \%) & $50.0 \%$ \\
\hline $30-39$ & 398/2010 (19.8\%) & $31.1 \%$ & $55 / 2010$ (2.7 \%) & $13.5 \%$ & 1557/2010 (77.5 \%) & $55.4 \%$ \\
\hline $40-49$ & $333 / 1475$ (22.6 \%) & $30.8 \%$ & 57/1475 (3.9 \%) & $12.5 \%$ & 1085/1475 (73.6 \%) & $56.7 \%$ \\
\hline $50-59$ & 136/530 (25.7 \%) & $30.8 \%$ & $32 / 530(6.0 \%)$ & $12.8 \%$ & $362 / 530$ (68.3 \%) & $56.4 \%$ \\
\hline $60+$ & 22/81 (27.2 \%) & $27.9 \%$ & 1/81 (1.2\%) & $13.5 \%$ & 58/81 (71.6 \%) & $58.6 \%$ \\
\hline \multicolumn{7}{|l|}{ Females } \\
\hline $20-29$ & 12/113 (10.6 \%) & $17.4 \%$ & 4/113 (3.5 \%) & $15.6 \%$ & 97/113 (85.8\%) & $67.0 \%$ \\
\hline 30-39 & 25/382 (6.5 \%) & $11.3 \%$ & 20/382 (5.2 \%) & $17.9 \%$ & 337/382 (88.2 \%) & $70.8 \%$ \\
\hline $40-49$ & 19/151 (12.6\%) & $12.8 \%$ & 17/151 (11.3\%) & $16.0 \%$ & 115/151 (76.2 \%) & $71.2 \%$ \\
\hline $50-59$ & 4/28 (14.3\%) & $11.9 \%$ & 3/28 (10.7 \%) & $20.2 \%$ & 21/28 (75.0 \%) & $68.0 \%$ \\
\hline \multirow[t]{3}{*}{$60+$} & 0/1 (0 \%) & $7.5 \%$ & 0/1 (0 \%) & $26.0 \%$ & $1 / 1(100 \%)$ & $66.5 \%$ \\
\hline & Risky Drinkers & $95 \% \mathrm{Cl}$ & Abstainers & $95 \% \mathrm{Cl}$ & Low risk Drinkers & $95 \% \mathrm{Cl}$ \\
\hline & Odds ratio & & Odds ratio & & Odds ratio & \\
\hline Males & 0.64 & $(0.60,0.69)$ & 0.25 & $(0.21,0.29)$ & 2.25 & $(2.11,2.39)$ \\
\hline Females & 0.67 & $(0.51,0.85)$ & 0.34 & $(0.25,0.46)$ & 2.32 & $(1.87,2.88)$ \\
\hline Overall & 0.59 & $(0.54,0.64)$ & 0.28 & $(0.24,0.33)$ & 2.30 & $(2.12,2.47)$ \\
\hline
\end{tabular}

${ }^{a}$ Risky drinkers were those who drank more than 2 standard drinks in a day

${ }^{b}$ No more than 2 standard drinks in a day

AUDIT scores $0=$ Abstainers, 1-7 = low risk drinkers, 8-15 = hazardous drinking, 16-19 = harmful drink, $\geq 20$ probable alcohol dependence 
Table 3 Drinking patterns by demographic characteristics in the Australian Defence Force sample - frequencies, weighted percentages, odds ratios and $95 \%$ confidence intervals

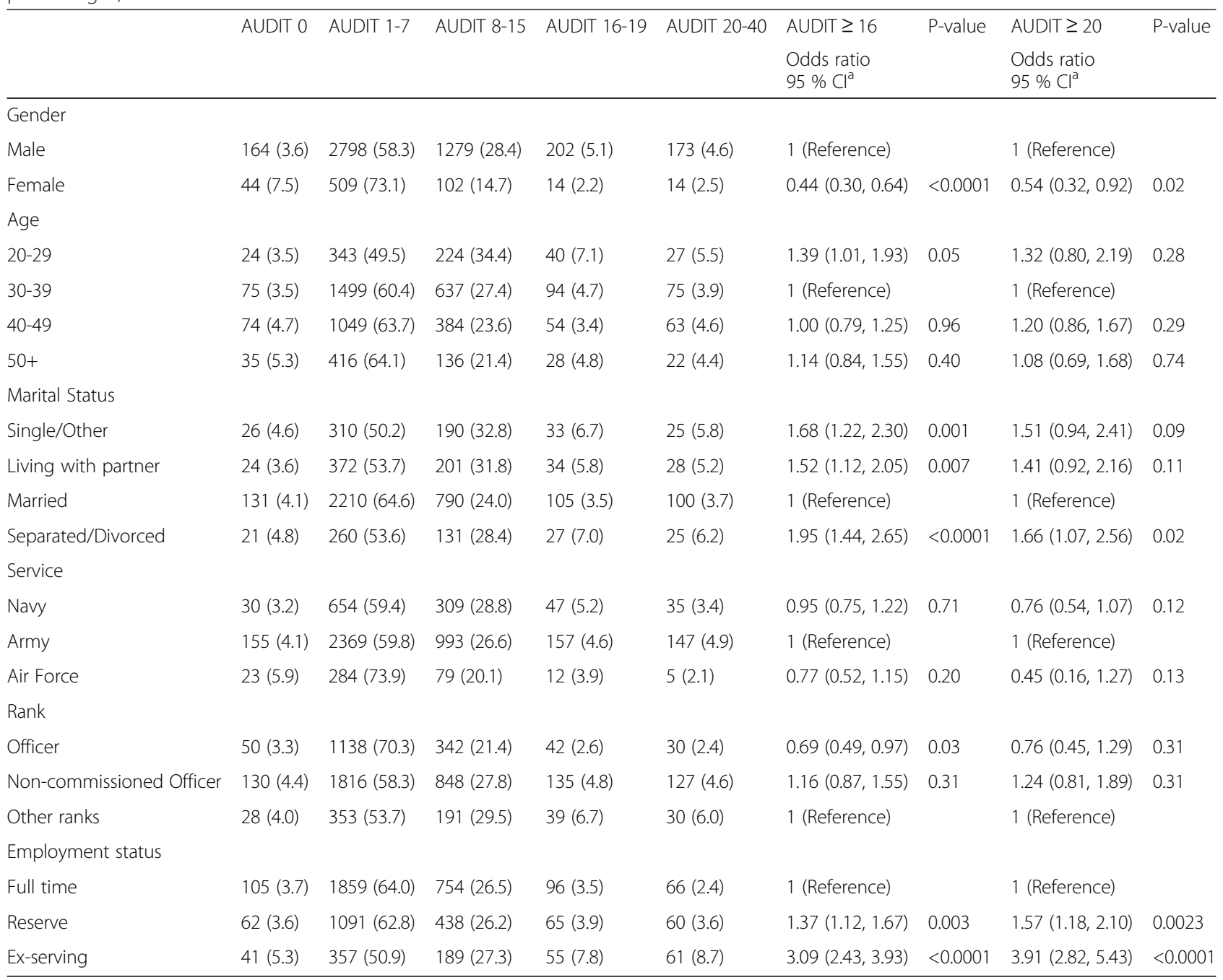

NB. AUDIT score $\geq 16$ also includes those with an AUDIT score $\geq 20$

a Odds ratios compare drinking behaviours between the categories of the demographic characteristics

responders drinking at a harmful level was similar across the older age groups (above the age of 30). Harmful drinking was most commonly reported among those with ranks below the officer level, reserves and exserving members. People who were married were less likely to report a harmful level of drinking. Harmful drinking was lower among Air Force personnel, however these differences were not statistically significant. Similar patterns were observed with alcohol dependence (AUDIT $\geq 20$ ), however, age group and lower rank were no longer statistically significantly associated with this behaviour. Binge drinking was also most common in men, those aged 20-29, Army, ex-serving members, and non-commissioned officers and lower ranks. Binge drinking was least common among Air Force and married responders (Table 4).

\section{Discussion}

In the results presented, alcohol misuse is clearly associated with poorer general health, increased difficulties and limitations with work and daily activities, and reduced social functioning in current and former members of the ADF. This suggests that alcohol consumption among Australian military personnel has the potential to limit Defence capacity. As such, strategies to reduce drinking within the ADF may be particularly beneficial in maintaining a healthy and productive workforce. While other studies have shown that alcohol misuse is associated with a lower level of functioning [10-13], the effects were typically observed in those who drink at a harmful level or are alcohol dependent.

Although low risk drinkers had slightly better health scores than abstainers, there was a gradual and 
Table 4 Binge drinking (6 or more drinks on one occasion) in the Australian Defence Force sample by demographic characteristics - frequencies, weighted percentages, odds ratios and $95 \%$ confidence intervals

\begin{tabular}{|c|c|c|c|c|c|c|c|c|c|}
\hline & \multirow[t]{2}{*}{ Never } & \multirow[t]{2}{*}{$\begin{array}{l}\text { Less than } \\
\text { monthly }\end{array}$} & \multirow[t]{2}{*}{ Monthly } & \multirow[t]{2}{*}{ Weekly } & \multirow{2}{*}{$\begin{array}{l}\text { Daily or } \\
\text { almost } \\
\text { daily }\end{array}$} & $\begin{array}{l}\text { Weekly or daily } \\
\text { binge drinking }\end{array}$ & \multirow[t]{2}{*}{$p$-value } & $\begin{array}{l}\text { Monthly or more } \\
\text { binge drinking }\end{array}$ & \multirow[t]{2}{*}{ p-value } \\
\hline & & & & & & $\begin{array}{l}\text { Odds ratio } \\
95 \% \mathrm{Cl}^{\mathrm{a}}\end{array}$ & & $\begin{array}{l}\text { Odds ratio } \\
95 \% \mathrm{Cl}^{\mathrm{a}}\end{array}$ & \\
\hline \multicolumn{10}{|l|}{ Gender } \\
\hline Male & $868(18.1)$ & 1931 (39.7) & $892(19.1)$ & $830(18.5)$ & $182(4.6)$ & 1 (Reference) & & 1 (Reference) & \\
\hline Female & $306(43.2)$ & $257(38.7)$ & $67(9.3)$ & $55(8.0)$ & $4(0.8)$ & $0.30(0.23,0.39)$ & $<0.0001$ & $0.27(0.22,0.32)$ & $<0.0001$ \\
\hline \multicolumn{10}{|l|}{ Age } \\
\hline $20-29$ & $84(12.3)$ & $255(35.4)$ & $184(27.5)$ & $141(22.4)$ & $13(2.4)$ & $1.21(0.96,1.51)$ & 0.10 & $1.65(1.38,1.97)$ & $<0.0001$ \\
\hline $30-39$ & $455(18.7)$ & $1080(43.7)$ & $446(18.3)$ & $374(16.0)$ & $61(3.3)$ & 1 (Reference) & & 1 (Reference) & \\
\hline $40-49$ & $408(24.7)$ & $658(39.2)$ & $235(13.7)$ & $274(17.0)$ & $77(5.3)$ & $1.20(1.04,1.39)$ & 0.01 & $0.91(0.81,1.03)$ & 0.15 \\
\hline $50+$ & $227(34.6)$ & $195(29.2)$ & $94(14.3)$ & $96(15.3)$ & $35(6.5)$ & $1.25(1.02,1.52)$ & 0.03 & $1.00(0.85,1.19)$ & 0.98 \\
\hline \multicolumn{10}{|l|}{ Marital Status } \\
\hline Single/Other & $83(13.0)$ & $222(39.3)$ & $119(20.4)$ & $129(23.8)$ & $15(3.5)$ & $1.66(1.33,2.05)$ & $<0.0001$ & $1.50(1.25,1.81)$ & $<0.0001$ \\
\hline Living with partner & $96(14.1)$ & $263(38.9)$ & $146(24.1)$ & $124(20.0)$ & $18(3.0)$ & $1.28(1.05,1.56)$ & 0.01 & $1.47(1.25,1.72)$ & $<0.0001$ \\
\hline Married & $667(20.4)$ & $1410(42.6)$ & $557(17.0)$ & $492(15.6)$ & $115(4.4)$ & 1 (Reference) & & 1 (Reference) & \\
\hline Separated/Divorced & $78(16.1)$ & 168 (36.6) & $87(20.2)$ & $87(19.5)$ & $28(7.5)$ & $1.43(1.16,1.76)$ & 0.0007 & $1.52(1.28,1.82)$ & $<0.0001$ \\
\hline \multicolumn{10}{|l|}{ Service } \\
\hline Navy & $192(17.4)$ & $480(43.5)$ & $210(19.5)$ & $176(16.5)$ & $31(3.0)$ & $0.84(0.72,0.98)$ & 0.03 & $0.99(0.87,1.13)$ & 0.91 \\
\hline Army & $867(21.8)$ & $1529(38.3)$ & $683(17.4)$ & $667(17.9)$ & $147(4.6)$ & 1 (Reference) & & 1 (Reference) & \\
\hline Air Force & $115(28.2)$ & $178(41.4)$ & $66(17.1)$ & $42(10.5)$ & $8(2.8)$ & $0.58(0.44,0.77)$ & 0.0002 & $0.77(0.64,0.92)$ & 0.004 \\
\hline \multicolumn{10}{|l|}{ Rank } \\
\hline Officer & $460(28.7)$ & $707(43.0)$ & $241(14.6)$ & $179(11.3)$ & $33(2.4)$ & $0.74(0.58,0.94)$ & 0.01 & $0.73(0.61,0.89)$ & 0.0013 \\
\hline Non-commissioned Officer & $595(19.5)$ & $1230(38.9)$ & $574(18.0)$ & $582(19.0)$ & $128(4.6)$ & $1.31(1.06,1.62)$ & 0.01 & $1.18(0.99,1.41)$ & 0.06 \\
\hline Other ranks & $117(17.4)$ & 247 (37.6) & $139(21.0)$ & $123(19.0)$ & $25(4.9)$ & 1 (Reference) & & 1 (Reference) & \\
\hline \multicolumn{10}{|l|}{ Employment status } \\
\hline Full time & $573(19.1)$ & $1242(42.2)$ & $572(19.8)$ & $474(16.6)$ & $67(2.3)$ & 1 (Reference) & & 1 (Reference) & \\
\hline Reserve & $437(24.5)$ & $708(40.4)$ & $274(15.9)$ & $268(15.7)$ & $60(3.5)$ & $1.09(0.96,1.23)$ & 0.20 & $0.97(0.87,1.07)$ & 0.51 \\
\hline Ex-serving & $164(21.5)$ & $238(34.1)$ & $113(16.7)$ & $143(19.7)$ & $59(8.0)$ & $1.67(1.39,2.00)$ & $<0.0001$ & $1.27(1.09,1.49)$ & 0.003 \\
\hline
\end{tabular}

NB Monthly or more binge drinking also includes those who binge drink weekly or daily

${ }^{a}$ Odds ratios compare drinking behaviours between the categories of the demographic characteristics

statistically significant decline in general health and social functioning, and more role limitations because of physical health problems, with increased alcohol misuse. The abstainers may contain a number of former drinkers who no longer drink because of previous problems with alcohol. However, it has also been hypothesised that abstainers may have poorer social relationships than light or moderate drinkers, which may contribute to poorer health in this group [30].

While we controlled for demographic characteristics and smoking status, it is unclear to what extent alcohol use was a primary contributor to reduced health and functioning, or whether the responders may have been using alcohol to cope with other physical or mental health conditions which were also associated with poorer functioning. Longitudinal studies of alcohol use may help researchers to more clearly determine the order of these events.

Consistent with a number of other studies, married personnel were less likely than single persons to report harmful drinking and binge drinking [1, 31, 32], perhaps due to different social and recreational activities undertaken by married people [33]. Also consistent with previous research harmful drinking was most commonly observed among men $[6,34,31,32]$ and younger age groups (20-29 years) [14, 31]. In addition, we found that non-commissioned officers, lower ranks and reserve and ex-serving personnel were more likely to report harmful drinking. These subgroups were also most likely to report 'binge drinking' at least monthly.

It is unclear whether increased alcohol consumption among ex-serving members pre-dated (and perhaps 
contributed to) their departure from the Australian Military or if their alcohol use increased after discharge. Despite assurances of confidentiality, it is possible that members who left the Australian Military may have been more comfortable disclosing their alcohol consumption than serving members.

Overall Navy and Army personnel were more likely to report binge drinking at least monthly than Air Force personnel. Differences in alcohol use between the services may be due to differences in entry requirements and the occupational roles of each service, or to different drinking cultures in each group. Likewise differences in the nature of operational deployments between the services may also impact on drinking behaviours [35]. These results are consistent with other studies that have shown fewer alcohol problems among Air Force personnel [14, 32].

The subgroups identified as having more alcohol problems and who were more likely to binge drink, may benefit from specific interventions aimed to reduce supply and consumption of alcohol. Recent studies from Australia and the UK have shown that while overall alcohol consumption in the population has fallen in the past decade, alcohol related harm has continued to rise [36-38]. Therefore, it has been argued that as well as aiming to reduce overall consumption, specific and targeted interventions are required to change the behaviour of the 'hardened drinkers' [37].

There were fewer current and former ADF members who drank more than 2 standard drinks a day than in the general Australian population. There were also fewer abstainers among current and former Australian Military members, but more people who drank at a lower risk level, than in the general Australian population. It has been suggested that a large proportion of the costs to the ADF associated with drinking may be attributable to 'low risk drinkers' who occasionally drink heavily [39]. In our analysis, more than $25 \%$ of the low risk drinkers (who averaged less than 2 standard drinks per day) reported 'binge drinking' at least monthly. However, this group, were not shown to have worse health and functioning outcomes, compared to 'low risk riskers' who did not 'binge drink'. A culture of social drinking and events in the ADF may explain why there were fewer abstainers. In contrast the finding of fewer risky drinkers in the ADF group may be due in part to a 'healthy soldier effect,' stemming from a requirement to maintain a good standard of fitness while serving [40].

The study reported a slightly higher percentage of serving members drinking above the harmful level $(5.9 \%$, AUDIT $\geq 16)$ than a 2010 of serving ADF members ( $3.7 \%$, AUDIT $\geq 16$ ) [19]. Comparing our findings with the international literature, we found that the percentage of males with a high level of alcohol problems was lower than observed in a UK study of military personnel conducted in 2003 (16\%, AUDIT $\geq 16)$ [11], but the percentages drinking more than 2 standard drinks per day were higher than reported in studies of US military personnel [41, 42]. In a comparison of drinking behaviours between US and UK military personnel, Sundin et al highlighted that the commanddirected alcohol treatment program and a military wide campaign to reduce alcohol consumption, may have contributed to reduced alcohol misuse in the US military, relative to other countries [43].

The result that fewer ADF members drank more than 2 standard drinks a day than in a sample of Australian civilians, contrasts with some US and UK studies that have reported more heavy alcohol users in military personnel compared to civilians [42, 14]. These results are inconsistent with other US and UK studies which found fewer differences in drinking patterns between veterans and those without military experience [41, 44]. Different outcome measures used to measure alcohol misuse in each study, as well as different levels of drinking in the population of each country [45], may explain some of the differences in findings. Although the prevalence of drinking and alcohol misuse varies between UK, US and Australian studies, research has indicated that a there is a perceived culture of drinking within the Defence Forces of each of these countries $[43,46,14,41]$. Therefore the findings presented from the ADF may also be useful to inform strategies in other militaries.

Changing drinking behaviours within military groups is likely to be challenging given established behaviours and practices developed over a number of years. The suggestion that drinking is seen to be an important catalyst for cohesion in military groups [2] is another potential barrier in reducing alcohol use. Nevertheless, since these data were collected (2008-2009), the ADF has commissioned an independent report on 'Use of Alcohol in the Australian Defence Force' [46] and developed an Alcohol Management Strategy. The report made a series of recommendations, encouraged a proactive (as opposed to reactive) approach, and endorsed an overall preventative stance with regard to alcohol use. One notable policy recommendation from the independent report was to change the focus of alcohol use in the ADF, so that instead of decisions being made about the situations where alcohol should be banned, decisions should be based on the question 'in which situations should alcohol be permitted?' [46].

In 2013 the ADF also produced a "Leaders guide alcohol management" document, which highlighted the role of ADF supervisors at all levels in addressing alcohol related issues and how more senior members should lead by example by upholding particular standards of 
behaviour [47]. This guide is important, especially because our results indicated that non-commissioned officers had higher levels of binge drinking compared to other ranks.

As the data we presented pre-date a number of these initiatives, our results provide baseline data against which these preventative initiatives can be evaluated. Further follow-up of ADF cohorts would help detect whether there are meaningful changes in patterns of alcohol use of personnel and determine the effectiveness of any new policies introduced to reduce alcohol related harm.

The survey response rates were between $41 \%$ and $43 \%$, so there may be some response bias. In the analysis we have reported, where possible, results for nonresponse using weights defined by service, rank and employment status. The measures on alcohol use and health used were self-reported, as opposed to more objective measures. Although the survey was confidential, the levels of alcohol use presented may be underestimates if serving members underreported current alcohol use. However, previous studies have shown the AUDIT scale to be a valid measure [48].

\section{Conclusion}

Although the proportion of risky drinkers among current and former ADF members was shown to be lower than that observed in the general Australian population, reform of drinking practices within the ADF is likely to improve both health and performance. As well as focusing on broad strategies aimed at reducing drinking across their whole workforce, militaries may also benefit from strategies focused on those groups at highest risk of alcohol misuse and binge drinking.

\section{Additional files}

Additional file 1: Figure S1. Classification of weekly alcoho consumptions based on responses to the first two AUDIT questions. (DOCX $14 \mathrm{~kb}$ )

Additional file 2: Table S1. General health, role physical and social functioning, by alcohol use category (AUDIT scale) in the Australian Defence Force sample $(n=4503)$. (DOCX $15 \mathrm{~kb})$

Additional file 3: Table S2. General health, role physical and social functioning for binge drinkers and non-binge drinkers in the Australian Defence Force sample. (DOCX $16 \mathrm{~kb}$ )

Additional file 4: Table S3. Drinking behaviours in Australian Defence Force sample compared to the civilian sample (NDSHS) - ADF sample weighted for non-response. (DOCX 16 kb)

\section{Competing interests}

The authors declare that they have no competing interests.

\section{Authors' contributions}

MW undertook the statistical analysis and wrote the manuscript. AD and AM advised on the design of the analysis and the presentation and interpretation of the results. All authors have approved the final version of the manuscript.
Received: 17 November 2014 Accepted: 13 July 2015

Published online: 28 July 2015

\section{References}

1. Iversen A, Waterdrinker A, Fear N, Greenberg N, Barker C, Hotopf M, et al. Factors associated with heavy alcohol consumption in the U.K. armed forces: data from a health survey of Gulf, Bosnia, and era veterans. Mil Med. 2007;172(9):956-61.

2. Browne T, Iversen A, Hull L, Workman L, Barker C, Horn O, et al. How do experiences in Iraq affect alcohol use among male UK armed forces personnel? Occup Environ Med. 2008;65(9):628-33. doi:10.1136/oem.2007 .036830 .

3. Room R, Babor T, Rehm J. Alcohol and public health. Lancet. 2005;365(9458):519-30. doi:10.1016/S0140-6736(05)17870-2.

4. McKenzie DP, McFarlane AC, Creamer M, Ikin JF, Forbes AB, Kelsall HL, et al. Hazardous or harmful alcohol use in Royal Australian Navy veterans of the 1991 Gulf War: identification of high risk subgroups. Addict Behav. 2006;31(9):1683-94. doi:10.1016/j.addbeh.2005.12.027.

5. Marshall BD, Prescott MR, Liberzon I, Tamburrino MB, Calabrese JR, Galea S. Coincident posttraumatic stress disorder and depression predict alcohol abuse during and after deployment among Army National Guard soldiers. Drug Alcohol Depend. 2012;124(3):193-9. doi:10.1016/j.drugalcdep 2011.12.027

6. Mattiko MJ, Olmsted KL, Brown JM, Bray RM. Alcohol use and negative consequences among active duty military personnel. Addict Behav. 2011;36(6):608-14. doi:10.1016/j.addbeh.2011.01.023.

7. Macmanus D, Dean K, Al Bakir M, Iversen AC, Hull L, Fahy T, et al. Violent behaviour in U.K. military personnel returning home after deployment. Psychol Med. 2012;42(8):1663-73. doi:10.1017/S0033291711002327.

8. Fisher CA, Hoffman KJ, Austin-Lane J, Kao TC. The relationship between heavy alcohol use and work productivity loss in active duty military personnel: a secondary analysis of the 1995 Department of Defense Worldwide Survey. Mil Med. 2000;165(5):355-61.

9. Barker $C T$. The alcohol hangover and its potential impact on the UK armed forces: a review of the literature on post-alcohol impairment. J R Army Med Corps. 2004;150(3):168-74.

10. Hanwella R, de Silva VA, Jayasekera NE. Alcohol use in a military population deployed in combat areas: a cross sectional study. Subst Abuse Treat Prev Policy. 2012;7:24. doi:10.1186/1747-597X-7-24.

11. Rona RJ, Jones M, Fear NT, Hull L, Hotopf M, Wessely S. Alcohol misuse and functional impairment in the UK Armed Forces: a population-based study. Drug Alcohol Depend. 2010;108(1-2):37-42. doi:10.1016/j.drugalcdep 2009.11.014

12. Erbes CR, Kaler ME, Schult T, Polusny MA, Arbisi PA. Mental health diagnosis and occupational functioning in National Guard/Reserve veterans returning from Iraq. J Rehabil Res Dev. 2011:48(10):1159-70.

13. McDevitt-Murphy ME, Williams JL, Bracken KL, Fields JA, Monahan CJ, Murphy JG. PTSD symptoms, hazardous drinking, and health functioning among U.S.OEF and OIF veterans presenting to primary care. J Trauma Stress. 2010;23(1):108-11. doi:10.1002/jts.20482.

14. Fear NT, Iversen A, Meltzer H, Workman L, Hull L, Greenberg N, et al. Patterns of drinking in the UK Armed Forces. Addiction. 2007;102(11): 1749-59. doi:10.1111/j.1360-0443.2007.01978.x.

15. Henderson A, Langston $V$, Greenberg N. Alcohol misuse in the Royal Navy. Occup Med (Lond). 2009;59(1):25-31. doi:10.1093/occmed/kqn152.

16. Bray RM, Marsden ME, Peterson MR. Standardized comparisons of the use of alcohol, drugs, and cigarettes among military personnel and civilians. Am J Public Health. 1991;81(7):865-9.

17. Polich JM. Epidemiology of alcohol abuse in military and civilian populations. Am J Public Health. 1981;71(10):1125-32.

18. Ballweg JA, Li L. Comparison of health habits of military personnel with civilian populations. Public Health Rep. 1989;104(5):498-509.

19. McFarlane AC, Hodson SE, Van Hooff M, Davies C. Mental health in the Australian Defence Force: 2010 ADF Mental Health and Wellbeing Study: Full report, Department of Defence: Canberra 2011. http://www.defence. gov.au/Health/DMH/Docs/1MHPWSreport-Frontmatter.pdf. Accessed 13 July 2015.

20. McGuire A, Waller M, Bleier J, Loos C, Nielsen L, Cosgrove T, et al. Bougainville Health Study Project Completion Report Centre for Military and Veterans' Health, The University of Queensland 2009. http://www.camvh 
.org.au/Research/CMVHBougainvilleHealthStudyReport.pdf. Accessed 13 July 2015.

21. McGuire A, Waller M, Bleier J, Loos C, Nielsen L, Cosgrove T, et al. East Timor Health Study Project Completion Report Centre for Military and Veterans' Health, The University of Queensland 2009. http://www.camvh.org.au/ Research/CMVHEastTimorHealthStudyReport.pdf. Accessed 13 July 2015.

22. 2010 National Drug Strategy Household Survey Report. Canberra: AlHWAustralian Institute of Health and Welfare 2011. http://www.aihw.gov.au/ workarea/downloadasset.aspx?id=10737421314. Accessed 13 July 2015.

23. Babor TFH, JC Saunders, JB Monteiro, MG AUDIT, The Alcohol Use Disorders Identification Test, Guidelines for Use in Primary Care: World Health Organisation, Department of Mental Health and Substance Dependence 2001. http://whqlibdoc.who.int/hq/2001/who_msd_msb _01.6a.pdf. Accessed 13 July 2015.

24. Anderson P, Cremona A, Paton A, Turner C, Wallace P. The risk of alcohol. Addiction. 1993;88(11):1493-508.

25. Reinert DF, Allen JP. The alcohol use disorders identification test: an update of research findings. Alcohol Clin Exp Res. 2007;31(2):185-99. doi:10.1111/ j.1530-0277.2006.00295.x.

26. Ware JEJ, Kosinski M, Gandek B. SF-36 Health Survey: Manual \& Interpretation Guide. Lincoln: QualityMetric Incorporated, 1993; 2000.

27. Wilson N, Weerasekera D, Collings S, Edwards R, van der Deen FS. Poorer mental health in many New Zealand smokers: national survey data from the ITC Project. The New Zealand medical journal. 2010;123(1326):129-32.

28. SAS Institute Inc. SAS version 9.3. Cary, NC, USA: SAS Institute Inc.

29. StataCorp. Stata Statistical Software: Release 10. College Station, Texas: StataCorp PL; 2007.

30. Lucas N, Windsor TD, Caldwell TM, Rodgers B. Psychological distress in non-drinkers: associations with previous heavy drinking and current social relationships. Alcohol Alcohol. 2010;45(1):95-102. doi:10.1093/alcalc/agp080.

31. Poehlman JA, Schwerin MJ, Pemberton MR, Isenberg K, Lane ME, Aspinwall K. Socio-cultural factors that foster use and abuse of alcohol among a sample of enlisted personnel at four Navy and Marine Corps installations. Mil Med. 2011;176(4):397-401.

32. Bray RM, Hourani LL. Substance use trends among active duty military personnel: findings from the United States Department of Defense Health Related Behavior Surveys, 1980-2005. Addiction. 2007;102(7):1092-101. doi:10.1111/j.1360-0443.2007.01841.x.

33. O'Malley PM. Maturing Out of Problematic Alcohol Use. National Institute on Alcohol Abuse and Alcoholism. http://pubs.niaaa.nih.gov/publications/ arh284/202-204.htm. Accessed 13 July 2015

34. Maguen S, Luxton DD, Skopp NA, Madden E. Gender differences in traumatic experiences and mental health in active duty soldiers redeployed from Iraq and Afghanistan. J Psychiatr Res. 2012;46(3):311-6. doi:10.1016/ j.jpsychires.2011.11.007.

35. Rona RJ, Fear NT, Hull L, Greenberg N, Earnshaw M, Hotopf M, et al. Mental health consequences of overstretch in the UK armed forces: first phase of a cohort study. BMJ. 2007;335(7620):603. doi:10.1136/bmj.39274.585752.BE.

36. Creagh S. Most Australians drinking less but heaviest drinkers boozing more The Conversation. 2013. http://theconversation.com/most-australians -drinking-less-but-heaviest-drinkers-boozing-more-17740. Accessed 13 July 2015.

37. Snowdon C. Drinking, heavy drinking and total consumption. Institute of Economic Affairs; 2013. http://www.iea.org.uk/blog/drinking-heavy -drinking-and-total-consumption. Accessed 13 July 2015

38. The Centre for Social Justice. No Quick Fix: Exposing the depth of Britain's drug and alcohol problem. UK: The Centre for Social Justice 2013. http:// www.centreforsocialjustice.org.uk/UserStorage/pdf/Pdf\%20reports/addict.pdf. Accessed 13 July 2015.

39. Pidd KJ, Berry JG, Roche AM, Harrison JE. Estimating the cost of alcohol-related absenteeism in the Australian workforce: The importance of consumption patterns. Med J Aust. 2006;185(11-12):637-41.

40. McLaughlin R, Nielsen L, Waller M. An evaluation of the effect of military service on mortality: quantifying the healthy soldier effect. Ann Epidemiol. 2008;18(12):928-36. doi:10.1016/j.annepidem.2008.09.002.

41. Bohnert AS, Ilgen MA, Bossarte RM, Britton PC, Chermack ST, Blow FC. Veteran status and alcohol use in men in the United States. Mil Med. 2012;177(2):198-203.

42. Vander Weg MW, Cai X. Variability in veterans' alcohol use by place of residence. Am J Addict. 2012;21(1):31-7. doi:10.1111/j.1521-0391. 2011.00191.x
43. Sundin J, Herrell RK, Hoge CW, Fear NT, Adler AB, Greenberg N, et al. Mental health outcomes in US and UK military personnel returning from Iraq. Br J Psychiatry. 2014;204(3):200-7. doi:10.1192/bjp.bp.113.129569.

44. Woodhead C, Rona RJ, Iversen A, MacManus D, Hotopf M, Dean K, et al. Menta health and health service use among post-national service veterans: results from the 2007 Adult Psychiatric Morbidity Survey of England. Psychol Med. 2011;41(2):363-72. doi:10.1017/S0033291710000759.

45. Global status report on alcohol and health 2014. WHO 2014. http:// www.who.int/substance_abuse/publications/global_alcohol_report/en/. Accessed 13 July 2015

46. Hamilton M. The Use of Alcohol in the Australian Defence Force: Report of the Independent Advisory Panel on Alcohol: Australian Government, Department of Defence 2011. http://www.defence.gov.au/pathwayto change/docs/useofalcohol/Review\%20of\%20the\%20Use\%20of\%20Alcohol\% 20in\%20the\%20ADF\%20full\%20report.pdf. Accessed 13 July 2015.

47. Australian Drug Foundation and the Australian Government Department of Defence, ADF Leaders Guide to Alcohol Management, Australian Defence Force Alcohol Management Strategy (ADFAMS) 2013. http://www.defence .gov.au/Health/Home/Docs/LeadersGuideFull.pdf. Accessed 13 July 2015.

48. Williams GD, Aitken SS, Malin H. Reliability of self-reported alcohol consumption in a general population survey. J Stud Alcohol. 1985:46(3):223-7.

\section{Submit your next manuscript to BioMed Central and take full advantage of:}

- Convenient online submission

- Thorough peer review

- No space constraints or color figure charges

- Immediate publication on acceptance

- Inclusion in PubMed, CAS, Scopus and Google Scholar

- Research which is freely available for redistribution

Submit your manuscript at www.biomedcentral.com/submit 